\title{
Evaluation of the Safety of Mine Road Based on Fuzzy Analytic Hierarchy Process
}

\author{
Chuhan Qin'1, Yingxue Zhang2* \\ ${ }^{1}$ Changsha Lushan International Experimental School, Changsha, China \\ ${ }^{2}$ School of Traffic and Transportation Engineering, Changsha University of Science \& Technology, Changsha, China \\ Email: *cscuzyx@126.com
}

How to cite this paper: Qin, C.H. and Zhang, Y.X. (2017) Evaluation the Safety of Mine Road Based on Fuzzy Analytic Hierarchy Process. Journal of Transportation Technologies, 7, 70-82. http://dx.doi.org/10.4236/jtts.2017.71005

Received: November 21, 2016

Accepted: January 8, 2017

Published: January 11, 2017

Copyright (c) 2017 by authors and Scientific Research Publishing Inc. This work is licensed under the Creative Commons Attribution International License (CC BY 4.0).

http://creativecommons.org/licenses/by/4.0/

cc) (i) Open Access

\begin{abstract}
Generally, mine roads are located in the mountain areas, as its complex topography, mostly along the river near the cliffs, steep bend anxious, the mine road design has to adopt lower technical standards relatively and usually is lack of traffic safety facilities. Especially, there are mainly medium-sized vehicles on mine road, under the heavy traffic vehicles affect repeatedly, high frequency of traffic accidents more easily happen in mine road area and cause serious effects on life or property. Combining with the particularity of mine road safety environment, this paper studies the basic theory of safety evaluation, analyses the factors of traffic safety design and special mine terrain conditions, and then establishes mine road safety index system and evaluation model based on the principles such as systematicness, independent indexes, qualitative and quantitative analysis, feasibility, scientificity and reliability. At last, the paper successfully evaluates the safety of road in Huang Mailing phosphate rock area with fuzzy AHP method based on engineering project.
\end{abstract}

\section{Keywords}

Mine Road, Safety Evaluation, Index System, Fuzzy Analytic Hierarchy

Process, Evaluation Model

\section{Introduction}

Usually mine road is located in mountain areas with low technical design standards winding along complex topography, mostly near river or cliffs, or steep bend anxious. And generally as it is used as a temporary road which paved with gravel and lack of traffic safety facilities, it causes heavy dust, large damage, poor conditions and large maintenance [1]. At the same time, as the heavy vehicles action on mine road repeatedly, it often results high frequency traffic accident, 
this directly influences the economic benefit of mine area, even causes losses to the national economy and people's life and property, brings serious adverse effects [2].

In order to ensure highway traffic safety, traffic scholars do a lot of researches on the causes of traffic accidents and the factors, factors cause accidents as highway alignment design, traffic safety facilities, drivers, etc. The main cause of the accident is due to the driver's fault (up to $87 \%$ ), which is considered to be the key of the road alignment conditions, traffic conditions and other factors in the accident. In fact, this is not reasonable, it will make the road workers take full responsibility attributed to others, and when design road, in order to reduce the cost and benefit, the consequences of doing so cannot guarantee the safety of road traffic ([3] [4]). Considering the complex terrain and traffic of mine road, the paper deeply analyses road traffic accidents reasons and evaluates the safety factors, puts forward improvement measures. This result is also significant for the mine road construction ([5] [6]).

\section{Basic Principles of Safety Evaluation}

\subsection{Overview of Safety Evaluation}

Safety evaluation is to use system engineering theory to identify and analyze the existence of risk factors, including the identification of risk factors and the degree of hazard assessment. The safety evaluation contents are shown in Figure 1.

In engineering practice, the two factors of risk degree and risk factor are closely related. According to the safety accidents distribution of mine road and cause analysis, the paper mainly studies from the following two aspects:

1) Hazard identify

Source of hazard: to confirm that there are no new hazard sources, and the change of danger.

Quantify risk: probability of risk.

2) Hazard degree assessment

Identify indexes and establish the value of danger.

Hazard control.

\subsection{Safety Evaluation Flow Diagram}

Safety evaluation flow diagram includes preliminary preparation, hazard identification and analysis, qualitative and quantitative analysis, safety measures and safety summary, the analysis flow diagram is shown in Figure 2.

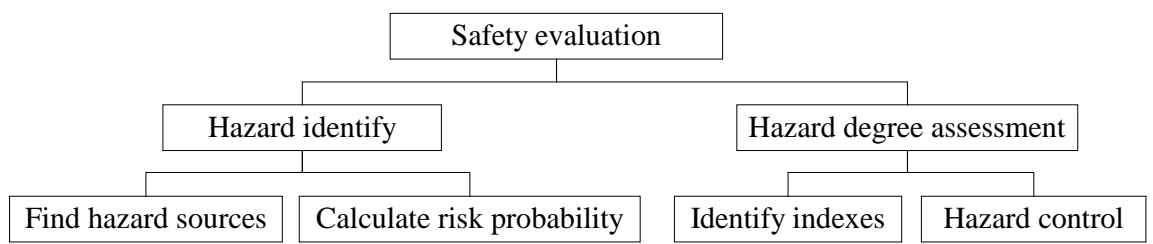

Figure 1. safety evaluation contents. 


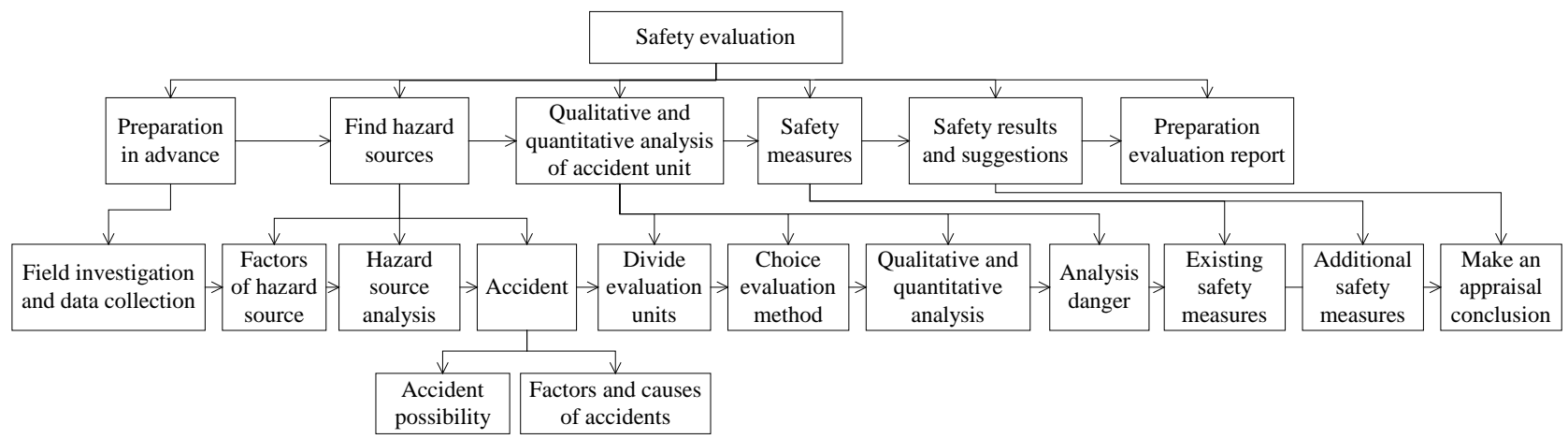

Figure 2. Evaluation flow diagram.

\section{Fuzzy Comprehensive Evaluation Based on Analytic Hierarchy Process}

\subsection{Safety Evaluation Model of Mine Road}

Fuzzy comprehensive evaluation is based on the evaluation criteria and the measured values. It is a method to evaluate the influence of many factors of the things or phenomena after the fuzzy transformation. There are $n$ factors related to the evaluation things, it can be recorded as $U=\left\{u_{1}, u_{2}, \cdots, u_{n}\right\}$ which is called factor set or index set. According to the fuzzy analytic hierarchy process (F-AHP) evaluation theory ([5] [6] [7]), the paper establishes the mine road traffic safety evaluation system. Then combining with the weight system, the paper evaluates the mine road safety with multistage fuzzy comprehensive evaluation method. The safety evaluation of the model is shown in Figure 3.

\subsection{Safety Evaluation Index System}

Compared with other highways, mine road has its unique characteristics. In order to meet the general highway design, it must meet its special requirements. The basic principles for the safety evaluation system of the mine road are mainly in the following five aspects ([8] [9] [10]):

1) Systematic principle

Mine road is a complicated system closely relates to many factors as highway safety and highway alignment, pavement quality, line of sight, sign and marking, topography, traffic and etc. Therefore, it is needed to consider the overall analysis of the system of the highway safety status of the mine by the evaluation index system of the evaluation index system.

2) Independent indexes

Indexes are an important factor that can truly reflect the safety degree. When selecting the indexes, it must be ensured that they are independence in the same level, do not allow evaluating the same or similar content with multiple indexes.

3) The combination of qualitative and quantitative

It will be more favorable to make a comprehensive analysis for highway traffic safety combining with the qualitative and quantitative methods.

4) The principle of feasibility

In order to ensure the evaluation system can be implemented, the indexes are 


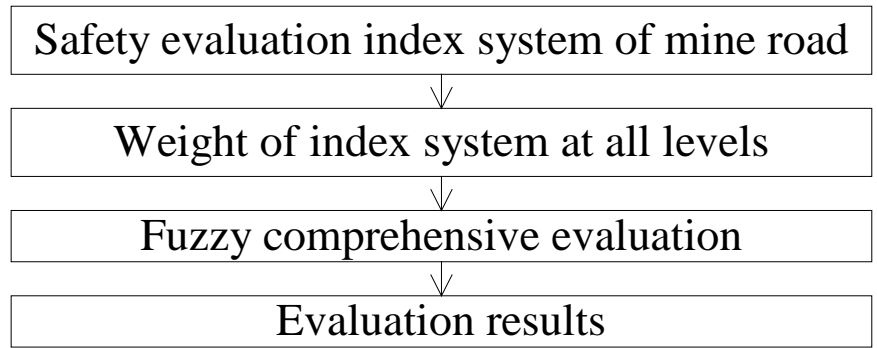

Figure 3. Traffic safety evaluation model of mine road.

chosen following the practical principles. According to the relevant files and field data collection, it is preliminary evaluated the feasibility of this safety index system to ensure the evaluation successfully.

5) The principles of science and reliability

In order to improve the management level of highway safety operation and ensure the realization of the overall goal of highway construction, it is necessary to evaluate the safety of highway alignment design and safety facilities. It is an important part of achieving this goal to ensure the scientific and reliability of indexes.

This paper establishes traffic safety evaluation system of mine road according to the above five principles and meets both the primary and secondary factors and all possible factors. The index system is as follows.

1) First-level indexes

They are the highest level factors for safety evaluation, including the external environmental indexes U1, safety facilities management indexes U2, technical safety indexes U3, and each of them has its own sub-indexes.

2) Second-level indexes

Second-level indexes are established on the further classification of primary indexes. They include topography $U_{11}$, climate $U_{12}$ and traffic volume $U_{13}$, pedestrian and other interference factors $U_{14}$; lighting $U_{21}$, guardrail $U_{22}$, marker $U_{23}$, marking $\mathrm{U}_{24}$ and other aspects of security management $\mathrm{U}_{25}$; sight distance $\mathrm{U}_{31}$, subgrade and pavement performance $U_{32}$ and road alignment $U_{33}$. The evaluation system framework is shown in Figure 4.

\subsection{The Steps of Fuzzy Analytic Hierarchy Process}

The main factors of mine road accidents include vehicle performance, driver, traffic condition, management and maintenance and environment based on the investigation of the existing highway safety. Of which the driver is the most important factor for traffic accidents. In this paper, the design of safety is mainly from the road alignment, protective facilities, operating environment and other aspects to optimize ([11] [12]). Therefore, in the safety design and evaluation of some mine road, the main steps are shown as follows.

1) Establish appropriate hierarchical structure

Hierarchical structure is shown as Figure 5.

2) Establish the corresponding comparison matrix at each level. Assume the 
first level of element $C_{k}$ ( $C_{k}$ is any element of the rule layer) as the criterion, it can dominate the next level elements, according to the importance of $C_{k}$, distribute the corresponding weights to the next level. In order to make the judgment quantitative and form the judgment matrix of the highway safety evaluation of the project, the $1 \sim 9$ scale method is adopted, as shown in Table 1.

3) Using the root square method to determine the weight. The steps of the method are as follows:

a) Calculate the product $M_{i}$ of each row element $c_{i j}$ in the judgment matrix.

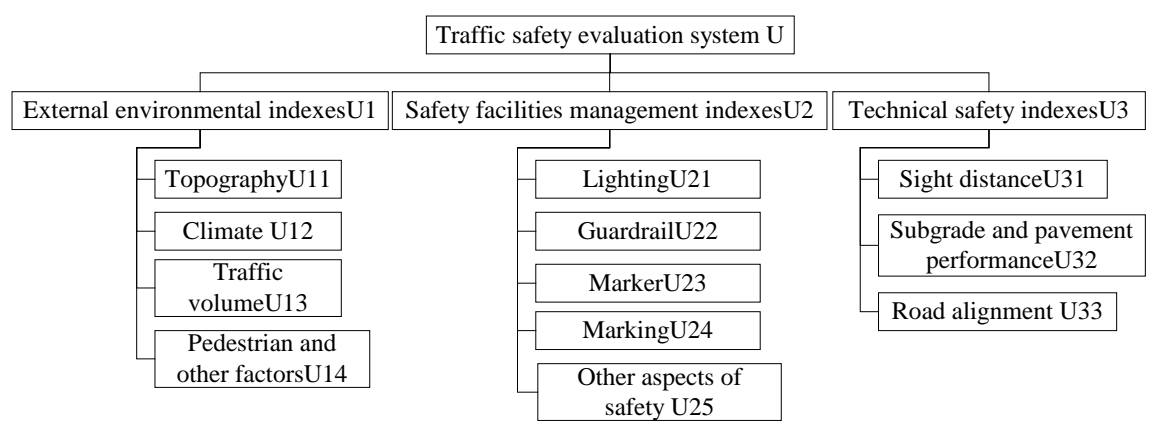

Figure 4. Safety evaluation indexes system of mine roa.

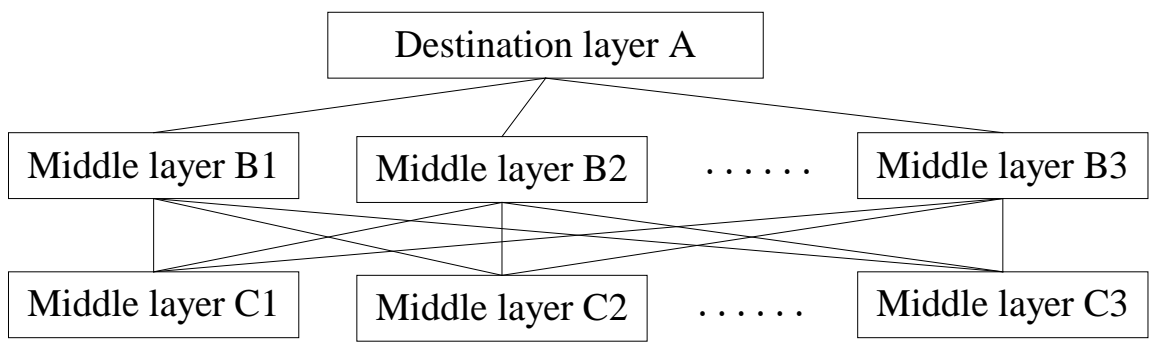

Figure 5. Hierarchical structure.

Table 1. Judgment matrix scale and its meaning.

\begin{tabular}{ccc}
\hline Serial number & Important hierarchy & $c_{i j}$ assignment \\
\hline 1 & Both elements $i$ and $j$ are equally important & 1 \\
2 & Of the two elements $i$ and $j, i$ is a little important & 3 \\
3 & Of the two elements $i$ and $j, i$ is obviously important & 5 \\
4 & Of the two elements $i$ and $j, i$ is highly important & 7 \\
5 & Of the two elements $i$ and $j, i$ is extremely important & 9 \\
6 & Of the two elements $i$ and $j, i$ is not important & $1 / 3$ \\
7 & Of the two elements $i$ and $j, i$ is obviouslynot & $1 / 5$ \\
8 & Of the two elements $i$ and $j, i$ is strongly not important & $1 / 7$ \\
9 & Of the two elements $i$ and $j, i$ is extremely not impor- & $1 / 9$ \\
\hline
\end{tabular}

Notes: when $C_{i j}$ gets the value of 2 or 4 or 6 or 8 , it is an intermediate value between the adjacent cases. 


$$
M_{i}=\prod_{j=1}^{n} c_{i j} \quad i=1,2,3, \cdots, \mathrm{n}
$$

b) Calculate the n-th root $\beta_{i}$ of $M_{i}$

$$
\beta_{i}=\sqrt[n]{M_{i}}
$$

c) Normalize the vector of $\beta=\left(\beta_{1}, \beta_{2} \cdots \beta_{n}\right)^{T}$

$$
w_{j}=\frac{\beta_{j}}{\sum_{j=1}^{n} \beta_{j}}(j=1,2,3, \cdots, \mathrm{n})
$$

The vector $w=\left(w_{1}, w_{2} \cdots w_{n}\right)^{T}$ is the desired feature vector.

d) Calculate the largest eigenvalue $\lambda_{\max }$ of judgment matrix

$$
\lambda_{\max }=\frac{1}{n} \sum_{i=1}^{n} \frac{(C w)_{i}}{w_{i}}
$$

For any $i=1,2,3, \cdots, n$, the $(C w)_{i}$ is the No. $i$ element of $w$ vector.

4) Carry out a single sorting, and do the consistency test. The formula for consistency indexes of judgment matrix is as following:

$$
C I=\lambda_{\max }-n / n-1
$$

5) Using the single level sorting results to test the results of the total sorting. These two steps are carried out from the highest level to the lowest level, and the random consistency ratio is calculated as following:

$$
C R^{(k)}=\frac{C I^{(k)}}{R I^{(k)}}
$$

Among them, the average random consistency index $R I$ which corresponds $n$ is obtained by the corresponding order according to the reference table of average random consistency index RI value of AHP [13], as shown in Table 2.

When CR $(k)<0.1$, it is good for the overall consistency of the judgment matrix and can be acceptable, otherwise, it needs to revise the judgment matrix until it meets the requirements.

\section{Application of Engineering Example}

\subsection{Geology Condition Evaluation}

1) Earthquake intensity and magnitude

The seismic fortification intensity is 6 degrees in the mining area and the nearby area, and the basic seismic acceleration is $0.05 \mathrm{~g}$. The crust is relatively stable.

2) Environment geology condition

a) Slope stability: structure surface of slope bedding is well developed. Rock soil generally contains manganese carbonaceous schist, carbon slices rock and

Table 2. Average random consistency index value.

\begin{tabular}{cccccccccc}
\hline Order & 1 & 2 & 3 & 4 & 5 & 6 & 7 & 8 & 9 \\
\hline RI & 0 & 0 & 0.59 & 0.91 & 1.12 & 1.24 & 1.33 & 1.41 & 1.43 \\
\hline
\end{tabular}


green schist soft inter layer, and rock of slope is along the slope, so the slope is easy instability when there appears large rainfall or obvious blasting vibration.

b) Landslide: because of very low mechanical strength and the small permeability coefficient of rock in mining area, when water immerges, the rock is easy to soften in the effect of gravity and some external factors, which may lead to mountain cracking, collapse, landslide and collapse.

c) Debris flow: there has accumulated about 22,028 thousand cubic meters waste rock, slag and tailings after over thirty years mined of mines. On the one hand, accumulation saturated by heavy rain will lose self-stability and causes creeping, this is a certain threat to the stability of slopes and natural drainage channels; on the other hand, surface water and mine water has a certain erosion effect. These two factors can easily cause geological disasters of debris flow.

d) Water resources and water environment: On the one hand, groundwater resource is dried up gradually because of the mine water drains out when mining. On the other hand, lixiviation water of phosphate rock contents of $\mathrm{S}$ ion, turbidity, suspended solids which exceed the standard, when it is drained with the mine water, it will pollutes the wild goose River and Huan water certainly nearby. Such will influence life water and agricultural live of nearby residents.

e) Land resources: the existing opencast pits, waste rocks and slag accumulation destroy and occupy part of the slope, accounting to $10 \%$ of the mining area. In the future of the mining process, waste rock, slag accumulation and mine water discharge will damage environmental and geological problems further.

f) Dust: A large number of mud, silt sand and harmful sulfur dust are produced during the process of mining, handling and transportation ore. These are very harmful for the mine workers and the environment around.

3) Geological environment impact assessment and type

Landslide is the main geo-environment problem of mining rock because of the development of mine geological environment. Local area may occur rock fall and mudslides may also occur as mine waste rock and slag stacking area, height, angle of steep slope in rainstorm. The exposed ore bodies have great influence on the surface structure, highway, underground water environment and natural landscape destruction, and the damage will be further increased after the underground mining in the future. Overall, the environmental geological conditions of the mining area is a complex type.

\subsection{Mine Road Safety Evaluation}

The formation lithology of the mining area is more complex, which is composed of solid and semi strong rocks, locally distributes unstable rock groups, and the engineering geological condition is of middle complex. The mining area appears a typical low hilly terrain, the overall scenery changes with mountain stretch and gully crossing landform. The new cement concrete pavement is $6 \mathrm{~m}$ wide and $1029 \mathrm{~m}$ long for secondary road, $4 \mathrm{~m}$ wide and $139 \mathrm{~m}$ long for access road. According to the characteristics, site conditions, technical data and experts opinion, the paper analyses the $1 \sim 9$ judgment matrix shown in Table 1 and ob- 
tains $\mathrm{U}-\mathrm{U}_{0}$ judgment matrix as shown in Table 3 .

$\mathrm{U}-\mathrm{U}_{0}$ hierarchy judgment matrix related parameters are calculated as follows:

1) Calculate the geometric average value of all elements of the $U-U_{0}$ hierarchy judgment matrix:

$$
\begin{aligned}
& \overline{\omega_{1}}=\sqrt[3]{1 \times \frac{1}{3} \times \frac{1}{7}}=0.362 \\
& \overline{\omega_{2}}=\sqrt[3]{3 \times 1 \times \frac{1}{5}}=0.843 \\
& \overline{\omega_{3}}=\sqrt[3]{7 \times 5 \times 1}=2.371
\end{aligned}
$$

2) Normalized calculation, then obtained the following:

$$
\begin{aligned}
& \omega_{1}=\frac{\overline{\omega_{1}}}{\sum \overline{\omega_{i}}}=\frac{0.362}{0.362+0.843+2.371}=0.101 \\
& \omega_{2}=\frac{\overline{\omega_{2}}}{\sum \overline{\omega_{i}}}=\frac{0.843}{0.362+0.843+2.371}=0.236 \\
& \omega_{3}=\frac{\overline{\omega_{3}}}{\sum \overline{\omega_{i}}}=\frac{2.371}{0.362+0.843+2.371}=0.663
\end{aligned}
$$

3) Calculate the maximum eigenvalue $\lambda_{\max }$ by using Matlab tool:

$$
\begin{gathered}
\lambda_{\max }=3.065 \\
C I=\frac{\lambda_{\max }-n}{\mathrm{n}-1}=0.0325
\end{gathered}
$$

From Table 2 , we can get $\mathrm{RI}=0.59$, so there is:

$$
\frac{C I}{R I}=\frac{0.0325}{0.59}=0.055<0.1
$$

Therefore, the $U-U_{0}$ judgment matrix meets the requirements of consistency verification.

Similarly, establishment $U_{1}-U_{00}$ judgment matrix, as shown in Table 4 .

Table 3. U - $\mathrm{U}_{0}$ judgment matrix.

\begin{tabular}{cccc}
\hline $\mathrm{U}$ & $\mathrm{U}_{1}$ & $\mathrm{U}_{2}$ & $\mathrm{U}_{3}$ \\
\hline $\mathrm{U}_{1}$ & 1 & $1 / 3$ & $1 / 7$ \\
$\mathrm{U}_{2}$ & 3 & 1 & $1 / 5$ \\
$\mathrm{U}_{3}$ & 7 & 5 & 1 \\
\hline
\end{tabular}

Table 4. $U_{1}-U_{00}$ judgment matrix.

\begin{tabular}{ccccc}
\hline $\mathrm{U}_{1}$ & $\mathrm{U}_{11}$ & $\mathrm{U}_{12}$ & $\mathrm{U}_{13}$ & $\mathrm{U}_{14}$ \\
\hline $\mathrm{U}_{11}$ & 1 & 3 & 5 & 7 \\
$\mathrm{U}_{12}$ & $1 / 3$ & 1 & 4 & 6 \\
$\mathrm{U}_{13}$ & $1 / 5$ & $1 / 4$ & 1 & 5 \\
$\mathrm{U}_{14}$ & $1 / 7$ & $1 / 6$ & $1 / 5$ & 1 \\
\hline
\end{tabular}


1) Calculate the geometric average value of all elements of the $U_{1}-U_{00}$ hierarchy judgment matrix:

$$
\begin{aligned}
& \overline{\omega_{1}}=\sqrt[4]{1 \times 3 \times 5 \times 7}=3.201 \\
& \overline{\omega_{2}}=\sqrt[4]{\frac{1}{3} \times 1 \times 4 \times 6}=1.682 \\
& \overline{\omega_{3}}=\sqrt[4]{\frac{1}{5} \times \frac{1}{4} \times 1 \times 5}=0.707 \\
& \overline{\omega_{4}}=\sqrt[4]{\frac{1}{7} \times \frac{1}{6} \times \frac{1}{5} \times 1}=0.263
\end{aligned}
$$

2) Normalized calculation, then obtained the following:

$$
\begin{aligned}
& \omega_{1}=\frac{\overline{\omega_{1}}}{\sum \overline{\omega_{i}}}=\frac{3.201}{3.201+1.682+0.707+0.263}=0.547 \\
& \omega_{2}=\frac{\overline{\omega_{2}}}{\sum \overline{\omega_{i}}}=\frac{1.682}{3.201+1.682+0.707+0.263}=0.287 \\
& \omega_{3}=\frac{\overline{\omega_{3}}}{\sum \overline{\omega_{i}}}=\frac{0.707}{3.201+1.682+0.707+0.263}=0.121 \\
& \omega_{4}=\frac{0.263}{\sum \overline{\omega_{4}}}=\frac{1.682+0.707+0.263}{\sum \overline{\omega_{i}}}=0.0449
\end{aligned}
$$

3) Calculate the maximum eigenvalue $\lambda_{\max }$ by using Matlab tool

$$
\begin{gathered}
\lambda_{\text {max }}=4.264 \\
C I=\frac{\lambda_{\text {max }}-n}{\mathrm{n}-1}=0.088
\end{gathered}
$$

From Table 2, we can get $R I=0.90$, so there is:

$$
\frac{C I}{R I}=\frac{0.088}{0.90}=0.098<0.1
$$

Therefore, the $U_{1}-U_{00}$ judgment matrix meets the requirements of consistency verification.

Similarly, establishment $U_{2}-U_{00}$ judgment matrix, as shown in Table 5 .

1) Calculate the geometric average value of all elements of the $U_{2}-U_{00}$ hierarchy judgment matrix

$$
\begin{aligned}
& \overline{\omega_{1}}=\sqrt[5]{1 \times \frac{1}{4} \times \frac{1}{2} \times \frac{1}{3} \times 5}=0.731 \\
& \overline{\omega_{2}}=\sqrt[5]{4 \times 1 \times 3 \times 5 \times 7}=3.347 \\
& \overline{\omega_{3}}=\sqrt[5]{2 \times \frac{1}{3} \times 1 \times \frac{1}{3} \times \frac{1}{2}}=0.644 \\
& \overline{\omega_{4}}=\sqrt[5]{3 \times \frac{1}{5} \times 3 \times 1 \times 2}=1.292 \\
& \overline{\omega_{5}}=\sqrt[5]{\frac{1}{5} \times \frac{1}{7} \times \frac{1}{3} \times \frac{1}{2} \times 1}=0.343
\end{aligned}
$$


2) Normalized calculation, then obtained the following:

$$
\begin{aligned}
& \omega_{1}=\frac{\overline{\omega_{1}}}{\sum \overline{\omega_{i}}}=\frac{0.731}{0.731+3.347+0.644+1.292+0.343}=0.115 \\
& \omega_{2}=\frac{\overline{\omega_{2}}}{\sum \overline{\omega_{i}}}=\frac{3.347}{0.731+3.347+0.644+1.292+0.343}=0.527 \\
& \omega_{3}=\frac{\overline{\omega_{3}}}{\sum \overline{\omega_{i}}}=\frac{0.644}{0.731+3.347+0.644+1.292+0.343}=0.101 \\
& \omega_{4}=\frac{\overline{\omega_{4}}}{\sum \overline{\omega_{i}}}=\frac{1.292}{0.731+3.347+0.644+1.292+0.343}=0.203 \\
& \omega_{5}=\frac{\overline{\omega_{5}}}{\sum \overline{\omega_{i}}}=\frac{0.343}{0.731+3.347+0.644+1.292+0.343}=0.0540
\end{aligned}
$$

3) Calculate the maximum eigenvalue $\lambda_{\max }$ by using Matlab tool

$$
\begin{gathered}
\lambda_{\max }=5.398 \\
C I=\frac{\lambda_{\text {max }}-n}{\mathrm{n}-1}=0.0995
\end{gathered}
$$

From Table 2, we can get $R I=1.12$, so there is:

$$
\frac{C I}{R I}=\frac{0.0995}{1.12}=0.0888<0.1
$$

Therefore, the $U_{2}-U_{00}$ judgment matrix meets the requirements of consistency verification.

Similarly, establishment $U_{3}-U_{00}$ judgment matrix, as shown in Table 6 .

$\mathrm{U}_{3}-\mathrm{U}_{00}$ hierarchy judgment matrix related parameters are calculated as follows:

1) Calculate the geometric average value of all elements of the $U_{3}-U_{00}$ hierarchy judgment matrix:

Table 5. $\mathrm{U}_{2}-\mathrm{U}_{00}$ Judgment matrix.

\begin{tabular}{cccccc}
\hline $\mathrm{U}_{2}$ & $\mathrm{U}_{21}$ & $\mathrm{U}_{22}$ & $\mathrm{U}_{23}$ & $\mathrm{U}_{24}$ & $\mathrm{U}_{25}$ \\
\hline $\mathrm{U}_{21}$ & 1 & $1 / 4$ & $1 / 2$ & $1 / 3$ & 5 \\
$\mathrm{U}_{22}$ & 4 & 1 & 3 & 5 & 7 \\
$\mathrm{U}_{23}$ & 2 & $1 / 3$ & 1 & $1 / 3$ & $1 / 2$ \\
$\mathrm{U}_{24}$ & 3 & $1 / 5$ & 3 & 1 & 2 \\
$\mathrm{U}_{25}$ & $1 / 5$ & $1 / 7$ & $1 / 3$ & $1 / 2$ & 1 \\
\hline
\end{tabular}

Table 6. $\mathrm{U}_{3}-\mathrm{U}_{00}$ Judgment matrix.

\begin{tabular}{cccc}
\hline $\mathrm{U}_{3}$ & $\mathrm{U}_{31}$ & $\mathrm{U}_{32}$ & $\mathrm{U}_{33}$ \\
\hline $\mathrm{U}_{31}$ & 1 & $1 / 2$ & $1 / 5$ \\
$\mathrm{U}_{32}$ & 2 & 1 & $1 / 3$ \\
$\mathrm{U}_{33}$ & 5 & 3 & 1 \\
\hline
\end{tabular}




$$
\begin{aligned}
& \overline{\omega_{1}}=\sqrt[3]{1 \times \frac{1}{2} \times \frac{1}{5}}=0.464 \\
& \overline{\omega_{2}}=\sqrt[3]{2 \times 1 \times \frac{1}{3}}=0.874 \\
& \overline{\omega_{3}}=\sqrt[3]{5 \times 3 \times 1}=2.466
\end{aligned}
$$

2) Normalized and obtained the following:

$$
\begin{aligned}
& \omega_{1}=\frac{\overline{\omega_{1}}}{\sum \overline{\omega_{i}}}=\frac{0.464}{0.464+0.874+2.466}=0.122 \\
& \omega_{2}=\frac{\overline{\omega_{2}}}{\sum \overline{\omega_{i}}}=\frac{0.874}{0.464+0.874+2.466}=0.230 \\
& \omega_{3}=\frac{\overline{\omega_{3}}}{\sum \overline{\omega_{i}}}=\frac{2.466}{0.464+0.874+2.466}=0.648
\end{aligned}
$$

3) Calculate the maximum eigenvalue $\lambda_{\max }$

$$
\begin{gathered}
\lambda_{\text {max }}=3.004 \\
C I=\frac{\lambda_{\text {max }}-n}{n-1}=0.002
\end{gathered}
$$

From above, we can get $R I=0.58$, so there is

$$
\frac{C I}{R I}=\frac{0.0325}{0.58}=0.00345<0.1
$$

Therefore, the $U_{3}-U_{00}$ judgment matrix meets the requirements of consistency verification.

According to the principle of AHP, we can reduce each index weight of the mine road safety evaluation system in the whole weight of the safety evaluation system, as shown in Table 7.

Checking consistency:

$$
\begin{gathered}
C I_{\text {total }}=0.101 \times 0.088+0.238 \times 0.0995+0.663 \times 0.002=0.0339 \\
R I_{\text {total }}=0.101 \times 0.90+0.238 \times 1.12+0.663 \times 0.58=0.742 \\
C R_{\text {total }}=0.0339 / 0.742=0.0457<0.1
\end{gathered}
$$

According to the weight value of each indexes in Table 7, the external environmental index $U_{1}$, safety facilities management $U_{2}$ and technical security $U_{3}$ are respectively $0.101,0.236$ and 0.663 , which indicates that the technical security is the biggest impact on mine road safety.

After analyzing the first level indexes, the paper finds the terrain and landforms index weight that takes over half is 0.547 in the environment safety index $\mathrm{U}_{1}$. So for this project, the terrain and landforms has the largest effect of mine road. The secondary indexes of lightings $U_{21}$, guardrails $U_{22}$, signs $U_{23}$, markings $\mathrm{U}_{24}$ and other safety facilities $\mathrm{U}_{25}$ are value $0.115,0.527,0.101,0.203$ and 0.054 respectively in the management index $U_{2}$. Thus, for the mine road mainly with truck vehicles, guardrail is the main safety factor of index $U_{2}$. In Technology security $\mathrm{U}_{3}$, sight distance, pavement performance and alignment are $0.122,0.230$ and 0.648 weight respectively. Considering all above values, we concludes again 
Table 7. Each index weight value.

\begin{tabular}{ccccc}
\hline & $\mathrm{U}_{1}$ & $\mathrm{U}_{2}$ & $\mathrm{U}_{3}$ & $\mathrm{~W}$ \\
\cline { 2 - 4 } & 0.101 & 0.236 & 0.663 & \\
\hline $\mathrm{U}_{11}$ & 0.547 & 0 & 0 & 0.182 \\
$\mathrm{U}_{12}$ & 0.287 & 0 & 0 & 0.096 \\
$\mathrm{U}_{13}$ & 0.121 & 0 & 0 & 0.040 \\
$\mathrm{U}_{14}$ & 0.0449 & 0 & 0 & 0.015 \\
$\mathrm{U}_{21}$ & 0 & 0.115 & 0 & 0.038 \\
$\mathrm{U}_{22}$ & 0 & 0.527 & 0 & 0.176 \\
$\mathrm{U}_{23}$ & 0 & 0.101 & 0 & 0.034 \\
$\mathrm{U}_{24}$ & 0 & 0.203 & 0 & 0.068 \\
$\mathrm{U}_{25}$ & 0 & 0.0540 & 0 & 0.018 \\
$\mathrm{U}_{31}$ & 0 & 0 & 0.122 & 0.041 \\
$\mathrm{U}_{32}$ & 0 & 0 & 0.230 & 0.077 \\
$\mathrm{U}_{33}$ & 0 & 0 & 0.648 & 0.216 \\
$\mathrm{C}_{\mathrm{ij}}$ & 0.088 & 0.0995 & 0.002 & \\
$\mathrm{R}_{\mathrm{ij}}$ & 0.90 & 1.12 & 0.58 & \\
\hline
\end{tabular}

that alignment design is the most important factor in road safety design, so when layout alignment and select design indexes, we should consider detail for different schemes and do a good safety protect measures.

The safety evaluation index of the mine road meet the consistency requirements by using the fuzzy comprehensive evaluation indexes to calculate and analyze.

\section{Conclusions}

In this paper, the fuzzy comprehensive evaluation method is used to evaluate the safety of mine road, and the main study results are concluded as following:

1) According to the safety particularity of mine road, based on the analysis and evaluation theory, the paper studies the safety evaluation process of mine road.

2) This paper establishes the evaluation index system of mine road safety based on the principle of system, independence, qualitative and quantitative analysis, feasibility, scientificity and reliability. It includes three first-level indexes as environment, safety management, and safety technology and 12 second level indexes.

3) Using the fuzzy analytic hierarchy process to evaluate the safety of mine road, the results show that the external environment index U1, safety facilities management $U_{2}$, and security technology $U_{3}$ are value $0.101,0.236$ and 0.663 respectively. Because of more difficult technical problem of mine road and higher design requirement, the designs of horizontal and longitudinal alignment, and cross section, pavement performance indexes occupy the maximum proportion, 
technical conditions is the largest impact factor for mine road safety.

\section{Acknowledgements}

The authors would like to thank Mr. Li Feng of Changsha Design and Research Institute of Chemical Industry Ministry who provides assistance in collecting engineering project data.

\section{References}

[1] Liu, J.G. (2001) Mechanism Analysis for Mine Roads Damage and the Way to Improve the Quality of Roads. Opencast Coal Mining Technology, 4, 57-59.

[2] Zhang, X.H. (1996) Influence of Mine Road Quality on the Cost and Efficiency of Automobile Transportation. Angang Mine, 3, 7-10.

[3] Liu, T. (2015) Research on the Relationship between Highway Design and Traffic Safety. Enterprise Technology Development, 30, 75-76.

[4] Zhang, C.X. (2015) Consideration of Traffic Safety Factors in Highway Design. Journal of Highway and Transportation Research and Development (Application Technology Edition), 11, 254-255.

[5] Yi, X. and Zhang, F.L. (2012) Comprehensive Evaluation of Construction Safety Management Based on Interval Number AHP and Vague Set. Journal of Safety and Environment, 12, 229-233.

[6] Zhang, Y.X. and Liu, Z.H. (2009) Route Evaluation Indexes of Changsha-Jishou Freeway for Protecting Cultural Heritages and Natural Environment. Journal of Environmental Science and Engineering, 3, 56-63.

[7] Zhang, Y.X., Han, C.H. and Zhang, Q.S. (2009) Decision-Making Model of Highway Route Plan Based on Entropy and Entropy Weight Theory. International Conference: Challenges and Recent Advances in Pavement Technologies and Transportation Geotechnics, 127-132. https://doi.org/10.1061/41042(349)16

[8] Liu, Y.D. (2016) The Application of Road Safety Concept in the Mountain Highway Design. Transportation Science \& Technology, 19, 56-57.

[9] Han, S. and Zhang, Q.L. (2015) Study on Settlement Regularity and Safety of Mining Highway in Near Collapse Area. Journal of Safety Science and Technology, 11, 126-129.

[10] Dahl, L.H.-R. (2004) Relationships between Accident Investigations, Risk Analysis, and Safety Management. Journal of Hazardous Materials, 111, 13-19.

[11] Zhang, Y.X. (2009) Analysis the Relation between Highway Horizontal Curve and Traffic Safety. 2009 International Conference on Measuring Technology and Mechatronics Automation, 479-481. https://doi.org/10.1109/ICMTMA.2009.511

[12] Easa, S.M. (2008) Optimizing Design of Highway Horizontal Alignments: New Substantive Safety Approach. Atif Mehmood Computer-Aided Civil and Infrastructure Engineering, 7, 156-159.

[13] Hou, L. (2014) Study on Safety Evaluation of Key Sections Design of Highway in Western Mountainous Area. Master's Degree Thesis, Chang'an University, Chang'an, 11-13. 
Submit or recommend next manuscript to SCIRP and we will provide best service for you:

Accepting pre-submission inquiries through Email, Facebook, LinkedIn, Twitter, etc. A wide selection of journals (inclusive of 9 subjects, more than 200 journals)

Providing 24-hour high-quality service

User-friendly online submission system

Fair and swift peer-review system

Efficient typesetting and proofreading procedure

Display of the result of downloads and visits, as well as the number of cited articles Maximum dissemination of your research work

Submit your manuscript at: http://papersubmission.scirp.org/

Or contact jtts@scirp.org 